\title{
Fuzzy Logic Operation Control for PV-Diesel-Battery Hybrid Energy System
}

\author{
Abd El-Shafy A. Nafeh* \\ Electronics Research Institute, Cairo, Egypt
}

\begin{abstract}
In this paper an operational control technique, based on using the fuzzy logic controller (FLC), is developed and applied to a proposed Photovoltaic-Diesel-Battery (PVDB) hybrid system. The proposed scheme is modeled and simulated using MATLAB-SIMULINK and FUZZY toolbox. The FLC is designed, to work simultaneously with the commonly used ON-OFF controller, for optimizing the operation of the PVDB system under different insolations. Where, the proposed system becomes able to reliably satisfy the system's load and, also, to optimize the battery and diesel operation at all working conditions. The results indicated the high capability of the FLC in controlling the system.
\end{abstract}

Keywords: PVDB hybrid system, Fuzzy logic control, MATLAB-SIMULINK.

\section{INTRODUCTION}

Throughout the world, there exist a number of small isolated communities, without access to an electricity grid. Extending utility grid to these people, in many cases is not cost effective. Electrical energy is usually provided in these cases by small to medium stand-alone diesel generators. The diesel generators have a low initial capital cost, but they are very expensive to run and maintain and contribute to the environmental pollution as every liter of diesel fuel releases about $3 \mathrm{~kg}$ of $\mathrm{CO}_{2}$ gas [1,2].

Combining renewable energy sources (such as photovoltaic (PV)) and conventional energy sources (such as diesel generator) with a battery bank for storage, forming a hybrid energy system, can provide an economic, environment friendly and reliable supply of electricity [1-5]. The requirement of the diesel generator in the system is to supplement the battery and the PV and to act as a back-up generator for extending periods of low renewable energy input or high load demand [1].

The operation control of such hybrid energy system is not a linear problem due to the nonlinear characteristics and the associated parameters variation of the constituent components. Therefore, the optimal operation control of such systems cannot be achieved easily using classical controllers, and hence a non classical or intelligent controller is indispensable.

Expert systems, fuzzy logic, neural networks and genetic algorithms belong to the area of artificial intelligence (AI), the $\mathrm{AI}$ is basically using human intelligence in a computer, so that a computer can think intelligently like a human, and these are recently finding wide applications in science and engineering problems [6].

For complex processes, it is difficult to obtain a reasonably good mathematical model. Fuzzy logic control based on operator experience is an ideal solution for applications

*Address correspondence to this author at the Electronics Research Institute, Cairo, Egypt; E-mails: abdelshafyn @eri.sci.eg, abdelshafyn@yahoo.com where a mathematical model is known or not precisely known especially for problems with varied parameters and nonlinear models [7].

Recently, fuzzy logic based control has been considered as one of the most active research area, that can control most PV applications, especially those of Photovoltaic-DieselBattery (PVDB) hybrid energy system. The PV arrays are characterized with highly nonlinear current-voltage curves according to the variation of solar insolation. The operation of the diesel engine and/or the battery is controlled when the output power from the PV array is not enough to satisfy the load. Since, the fuzzy logic controller (FLC) works well for complex ill-defined nonlinear systems, especially where parameter variation problem exists. Therefore, the application of the FLC for the operation of the PVDB hybrid energy system is well-suited. This paper designs the suitable FLC and ON-OFF controller for optimizing the developed operational control technique of the considered PVDB hybrid energy system, with the corresponding simulation results are indicated at the end of the paper.

\section{SYSTEM MATHEMATICAL MODEL}

\subsection{Solar Array Generator}

The terminal equation of the solar array is given by [8]:

$\mathrm{V}_{\mathrm{A}}=\mathrm{AV} \mathrm{V}_{\mathrm{T}} \ln \left[\left(\mathrm{I}_{\mathrm{Ph}}-\mathrm{I}_{\mathrm{A}}+\mathrm{I}_{\mathrm{r}}\right) / \mathrm{I}_{\mathrm{r}}\right]-\mathrm{I}_{\mathrm{A}} \mathrm{R}_{\mathrm{S}}$

Where: $\quad \mathrm{V}_{\mathrm{A}}$ array terminal voltage

$\mathrm{I}_{\mathrm{A}}$ array terminal current

$\mathrm{I}_{\mathrm{ph}} \quad$ array photo-generated current

$\mathrm{I}_{\mathrm{r}} \quad$ reverse saturation current

$\mathrm{R}_{\mathrm{s}} \quad$ array series resistance

A ideality factor

$\mathrm{V}_{\mathrm{T}}$ thermal voltage

Thus, the array power is given as the multiplication of array voltage $\mathrm{V}_{\mathrm{A}}$ by the array current $\mathrm{I}_{\mathrm{A}}$. Also, the array maximum power $\mathrm{P}_{\max }$ can be obtained as: 


$$
P_{\max }=V_{m p} \cdot I_{m p}
$$

Where: $\mathrm{V}_{\mathrm{mp}}$ array maximum-power voltage

$\mathrm{I}_{\mathrm{mp}}$ array maximum-power current

The maximum energy which can be extracted from the solar array throughout one-day period is given by:

$$
E_{\max }=\int_{t_{S r}}^{t_{S S}} P_{\max }(t) d t
$$

Where, $t_{\mathrm{sr}}$ is the sunrise time and $\mathrm{t}_{\mathrm{ss}}$ is the sunset time.

\subsection{Diesel Generator Set}

The relation between the diesel generator input fuel and output electrical power is assumed, here, to be linear. Another common 'rule of thumb' is the assumption that the fuel consumption at idling is approximately 25 to 30 per cent of the consumption at nominal rated power. The diesel plants have a clutch between the diesel engine and the generator. To be able to handle starts and stops of the diesel engine, the clutch must also be modeled.

The differential equations describing speed and fuel consumption in this model are [9]:

$$
\mathrm{d} \omega_{d} / d t=\left[K_{V}\left(K_{C} m_{f}-P_{O}\right)-D_{d} \omega_{d}-T_{d g e n}\right] / J_{d}
$$

and

$$
\mathrm{d} m_{f} / d t=\left[\omega_{d}-\omega_{r e f}-m_{f} / \delta\right] / T_{d}
$$

\section{The Symbols are:}

$\omega_{\mathrm{d}} \quad$ Engine speed

$\omega_{\text {ref }}$ Governor reference speed

$\delta \quad$ Governor gain constant

$\mathrm{T}_{\mathrm{d}} \quad$ Time constant in governor

$\mathrm{m}_{\mathrm{f}} \quad$ Diesel fuel consumption

$\mathrm{K}_{\mathrm{c}} \quad$ Constant describing efficiency of the combustion

$\mathrm{P}_{\mathrm{o}} \quad$ Motor chamber pressure when running idle

$\mathrm{K}_{\mathrm{v}} \quad$ Stroke volume

$\mathrm{T}_{\mathrm{p}} \quad$ Produced torque

$\mathrm{T}_{\mathrm{f}} \quad$ Friction torque

$\mathrm{T}_{\text {dgen }}$ Load torque from generator and clutch

$\mathrm{D}_{\mathrm{d}} \quad$ Constant describing the frictional losses

$\mathrm{J}_{\mathrm{d}} \quad$ Total moment of inertia of the engine, clutch and generator

\subsection{Battery Model}

The general equation for the used battery (24 Trojan L16) voltage $V_{B}$ and current $I_{B}$ during the charge/discharge processes is [10]:

$\mathrm{V}_{\mathrm{B}}=\mathrm{V}_{\mathrm{OC}} \pm I_{B} R_{B}$

$V_{B}=\left[V_{O}+K_{B} \frac{Q}{\frac{C_{T}}{1+a I_{B} b}\left(1+\alpha_{C} \Delta T+\beta_{C} \Delta T^{2}\right)}\right] \pm I_{B}\left[\left[\frac{P_{1}}{1+I_{B} P 2}+\frac{P_{3}}{\left[1-\frac{Q}{C_{T}}\right]^{P_{4}}}+P_{5}\right]\left(1-\alpha_{r} \Delta T\right)\right]$
Where, "+" stands for charge and "-” for discharge. In this equation:

$\mathrm{V}_{\text {oc }}$ battery open circuit voltage

$\mathrm{R}_{\mathrm{B}} \quad$ battery internal resistance

$\mathrm{V}_{\mathrm{o}} \quad$ initial voltage parameter

$\mathrm{Q}=\mathrm{I}_{\mathrm{B}} \mathrm{t} \quad$ Ah supplied

$\mathrm{C}=\mathrm{C}_{\mathrm{T}}\left(1+\alpha_{\mathrm{c}} \Delta \mathrm{T}+\beta \mathrm{c} \Delta \mathrm{T}^{2}\right) /\left(1+\mathrm{aI}_{\mathrm{B}}{ }^{\mathrm{b}}\right)$ capacity equation $\mathrm{P}_{1} /\left(1+\mathrm{I}_{2}^{\mathrm{P}}\right)+\mathrm{P}_{3} /\left[1-\mathrm{Q} / \mathrm{C}_{\mathrm{T}}\right]_{4}^{\mathrm{P}}+\mathrm{P}_{5}$ internal resistance term. Where, $a, b, V_{o}, K_{B}, P_{1}, P_{2}, P_{3}, P_{4}$, and $P_{5}$ are empirical parameters, $\alpha_{r}$ is the temperature coefficient of internal resistance, and $\Delta \mathrm{T}=\mathrm{T}-25^{\circ}$.

\section{THE CONTROL TECHNIQUE}

The main targets of the proposed operational control technique of the PVDB hybrid energy system are to reliably satisfy the load requirements, and at the same time to optimize the battery and diesel operation at all working atmospheric conditions. The block diagram of the proposed PVDB hybrid energy system with the associated control signals, to achieve these targets, is shown in Fig. (1). In this diagram, it is clear that the solar generator satisfies the load requirements continuously as long as there is adequate illumination. Also, it works independently of the other system components until the system controller (i.e., the designed FLC and the commonly used ON-OFF controller) takes the relevant decision to compensate the change in the load profile. The actual load power is used to optimally manage the system components, to continuously cover the desired load requirements in terms of the need to charge or discharge the battery as well as the need to plug in or plug out the diesel unit.

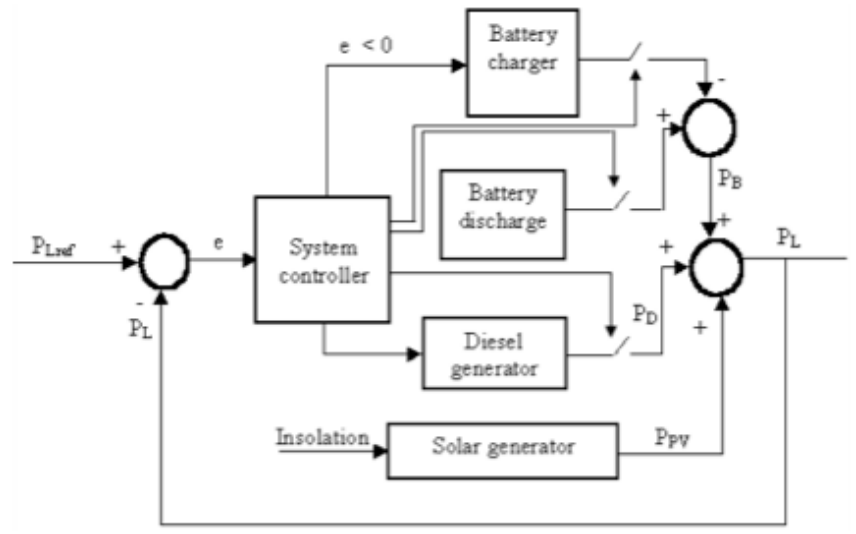

Fig. (1). Block diagram of the proposed PVDB hybrid energy system.

The interaction between the available solar insolation, the desired load profile, and the corresponding battery state of charge results in three different cases for operation control of the proposed hybrid energy system. These three cases are used, here, to make the system controller able to take the proper decision for the battery and/or the diesel generator 
Table 1. Different Cases for Operation Control of the Proposed Hybrid Energy System

\begin{tabular}{|c|c|c|c|}
\hline Case & System Error & Concluding Remark & Controller Action \\
\hline \hline 1 & $\mathrm{e}>0$ & $\mathrm{P}_{\mathrm{PV}}<\mathrm{P}_{\mathrm{Lref}}$ & $\begin{array}{c}\text { Safely discharge the battery and switch on diesel generator if the } \\
\text { battery power is not sufficient }\end{array}$ \\
\hline 2 & $\mathrm{e}=0$ & $\mathrm{P}_{\mathrm{PV}}+\mathrm{P}_{\mathrm{B}}+\mathrm{P}_{\mathrm{D}}=\mathrm{P}_{\mathrm{Lref}}$ & Remain the current control settings without change \\
\hline 3 & $\mathrm{e}<0$ & $\mathrm{P}_{\mathrm{PV}}>\mathrm{P}_{\mathrm{Lref}}$ & Safely charge the battery \\
\hline
\end{tabular}

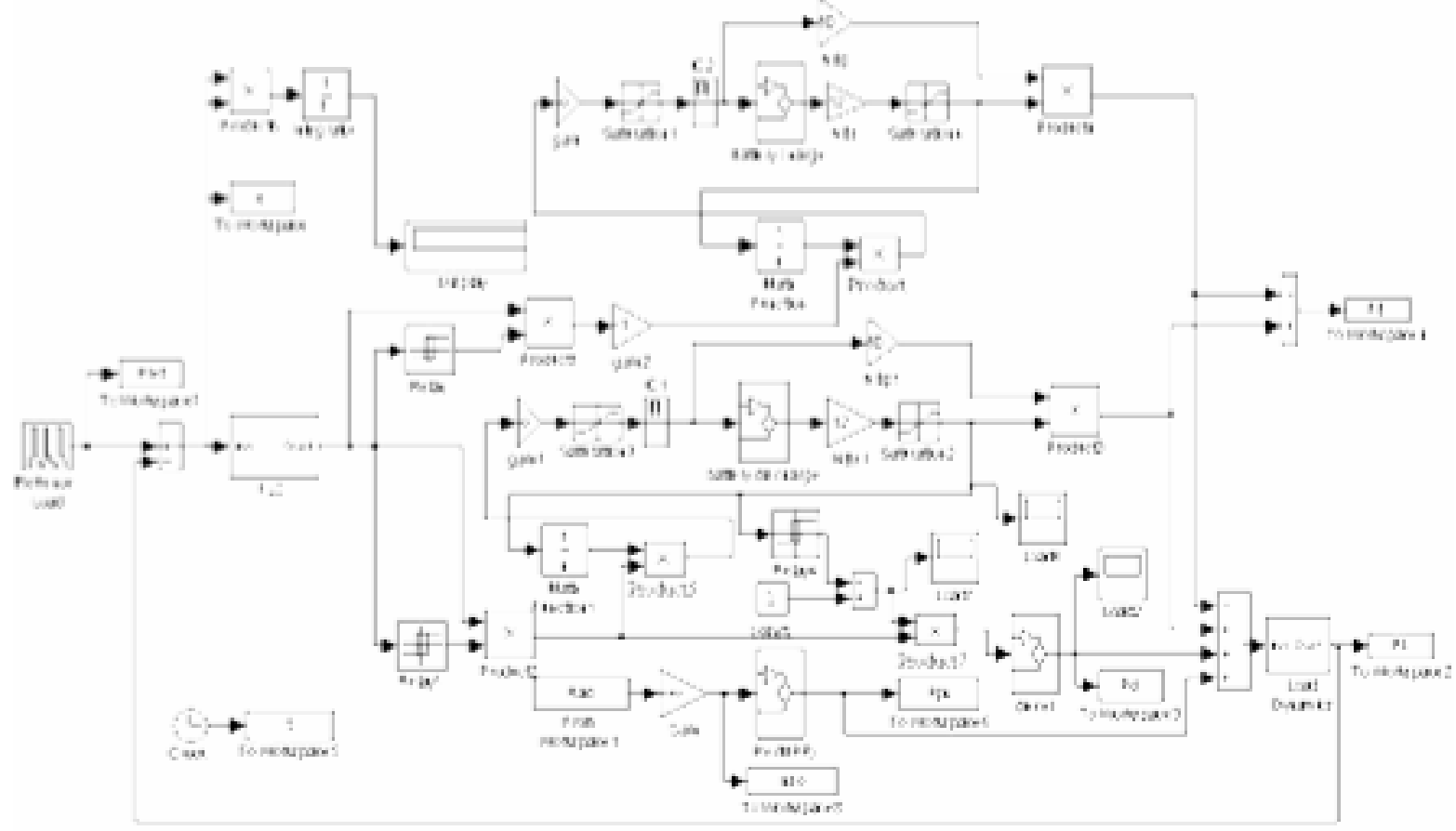

Fig. (2). SIMULINK model of the PVDB hybrid energy system with FLC.

and to reliably satisfy the load requirements. The three cases, which are summarized in Table $\mathbf{1}$, can be explained as follows. In case (1), the system error (i.e., the difference between the desired load power $\mathrm{P}_{\text {Lref }}$ and the actual load power $\mathrm{P}_{\mathrm{L}}$ ) is greater than zero, which means that the generated solar power $\mathrm{P}_{\mathrm{PV}}$ is lower than that required by the load. Thus, in this case the controller makes the battery discharge with the limiter discharger controller (in order not to exceed the maximum discharging limit) to supplement this deficit. At the same time the controller may switch on the diesel generator, if the battery power is not sufficient. In case (2), the system error equals to zero, which means that the load supplied power from the solar generator, the battery, and/or the diesel generator is just sufficient to satisfy the load requirements. Thus, in this case the controller remains the current control settings without change. While, in case (3), the system error is smaller than zero, which means that the generated solar power is greater than that required by the load. Thus, in this case the controller causes the battery to be charged with the limiter charge controller (in order not to exceed the maximum charging limit). Note, here, that the operation control of such hybrid energy system is not a linear problem due to the nonlinear characteristics and the associated parameters variation of the constituent components. Therefore, the optimal operation control of such systems can not be achieved easily using classical ON-OFF or PI controllers. Hence a non classical or intelligent controller that incorporates the action of both the FLC and the classical ON-OFF controller is proposed, to overcome the nonlinearity and parameter variation problems of the components included in the hybrid system, which greatly improves the performance of the system at transient and also ensures zero error at steady state condition.

\section{MATLAB SIMULATION AND FLC DESIGN}

The system mathematical models are used to construct the SIMULINK block diagram of the complete PVDB hybrid energy system, as shown in Fig. (2), by linking the individual models together. Also, the SIMULINK block diagram of the proposed FLC is shown in Fig. (3), which is a twoinput single-output controller. The FLC inputs are the error e and change of error $\Delta \mathrm{e}$, defined, respectively, by:

$\mathrm{e}(\mathrm{k})=\mathrm{P}_{\text {Lref }}(\mathrm{k})-\mathrm{P}_{\mathrm{L}}(\mathrm{k})$

and

$\Delta \mathrm{e}(\mathrm{k})=\mathrm{e}(\mathrm{k})-\mathrm{e}(\mathrm{k}-1)$

While, the FLC output is the change in control variable $\Delta \mathrm{u}(\mathrm{k})$, which is added to the previous control variable $\mathrm{u}(\mathrm{k}-1)$ to give the current control variable $\mathrm{u}(\mathrm{k})$, as 


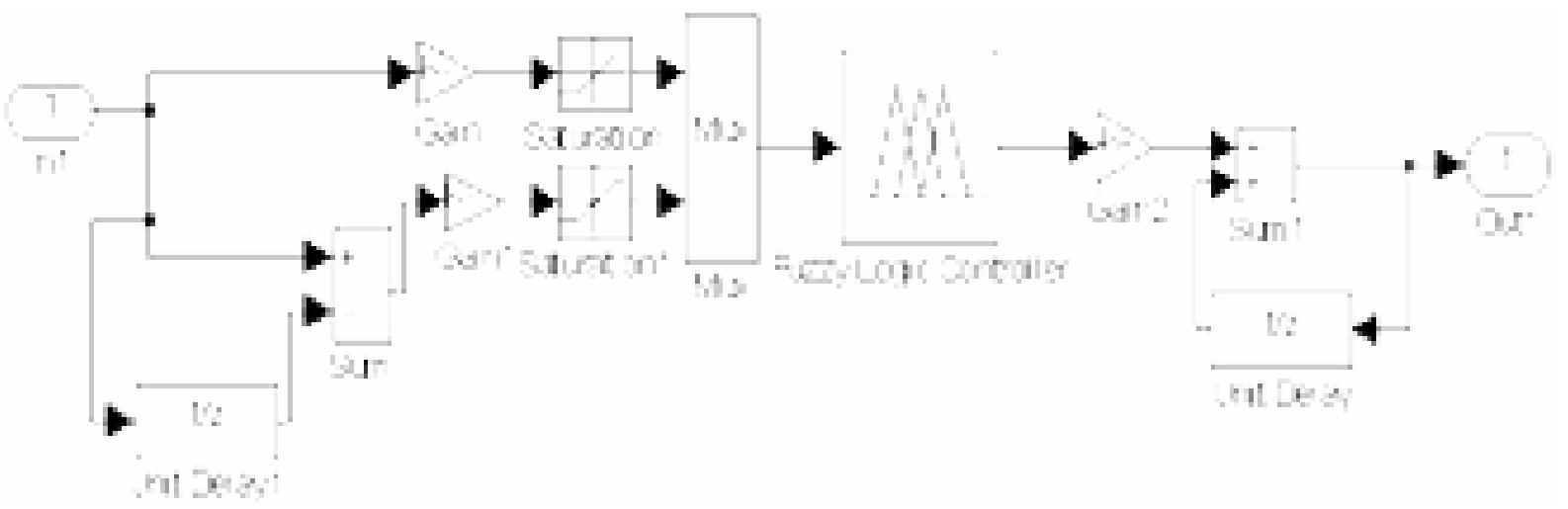

Fig. (3). SIMULINK block diagram of the FLC.
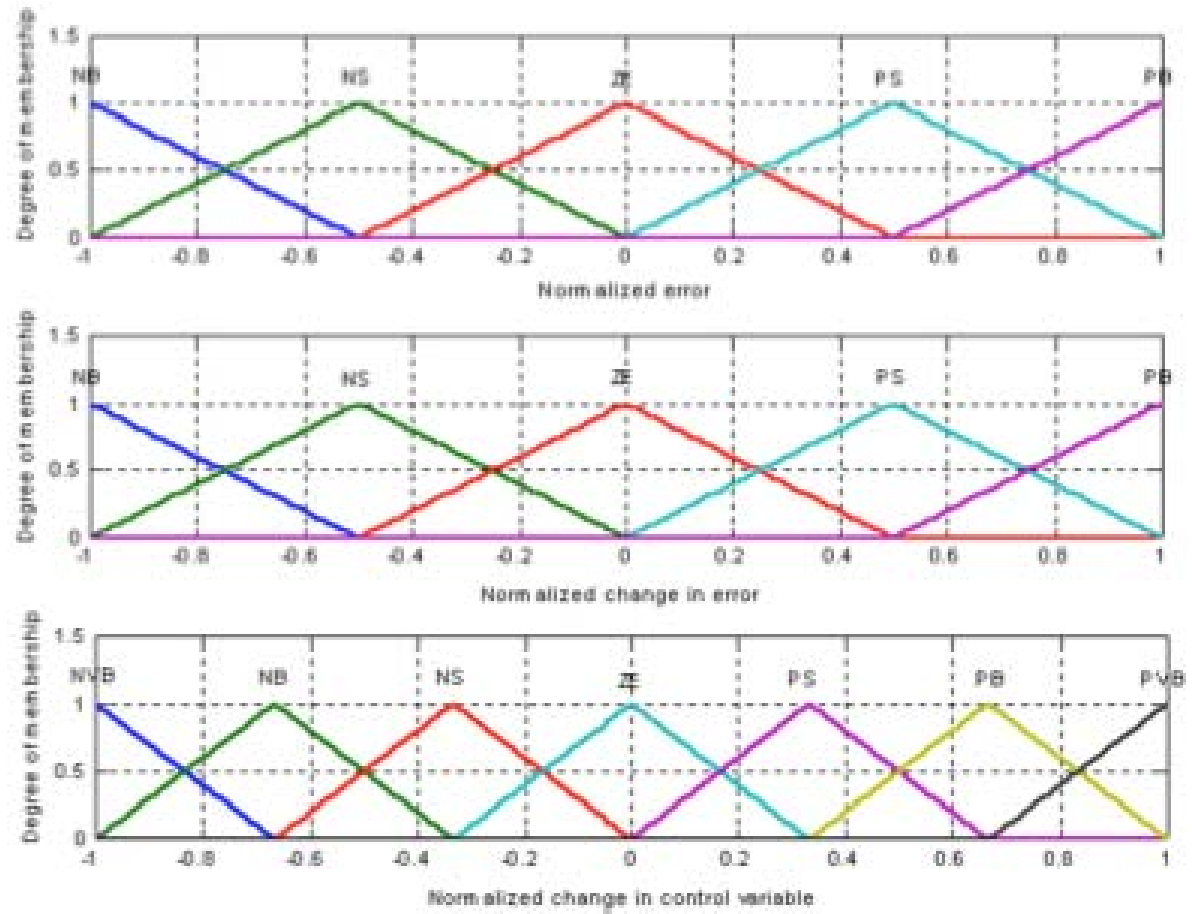

Fig. (4). Membership functions of the fuzzy variables.

$\mathrm{u}(\mathrm{k})=\Delta \mathrm{u}(\mathrm{k})+\mathrm{u}(\mathrm{k}-1)$

Where, $\mathrm{k}$ is sampling time. The design of the considered FLC is primary based on trial and error procedure. The triangular membership function (with $50 \%$ overlapping for the neighboring fuzzy subsets) is considered because of its simplicity of implementation and because less computational intensity is required. Since the sensitivity of a variable determines the number of fuzzy subsets associated to its membership function. Thus, due to the high sensitivity of the output variable $\Delta u$ over that of the input variables, a finer partitioning for its fuzzy subsets is necessary [11,12]. Fig. (4) indicates the membership functions of the input and output variables. In this case five subsets are used for both the input variables (e and $\Delta \mathrm{e}$ ), while seven subsets are used for the output control variable $(\Delta \mathrm{u})$. It is to be noted that the number of subsets of the output variable doesn't have an influence on the number of fuzzy control rules, but changes the response of the whole system significantly. The designed fuzzy control rules, expressed in a matrix form, are shown in Table 2. This table indicates that the considered number of rules is 25 . Where, the linguistic values of the used fuzzy subsets are defined as:

$$
\begin{array}{ll}
\mathrm{N} & \text { negative } \\
\mathrm{ZE} & \text { zero } \\
\mathrm{P} & \text { positive } \\
\mathrm{S} & \text { small } \\
\mathrm{B} & \text { big } \\
\mathrm{V} & \text { very }
\end{array}
$$

The parameters of the FLC (i.e., its scaling factors) are tuned using the trial and error iterative approach, until the optimal response of the PVDB hybrid system is obtained. The controller tuning is carried out at insolation level of 
Table 2. Rule Base of the FLC

\begin{tabular}{|c|c|c|c|c|c|}
\hline & NVB & NVB & ZE & PS & NS \\
\hline \hline NB & NVB & NB & NB & ZE & PS \\
\hline NS & NB & NB & ZE & PB & PB \\
\hline ZE & NB & NS PVB & PVB \\
\hline PS & NS & ZE & PB & PVB \\
\hline PB & ZE & PS & & PS & PB \\
\hline
\end{tabular}

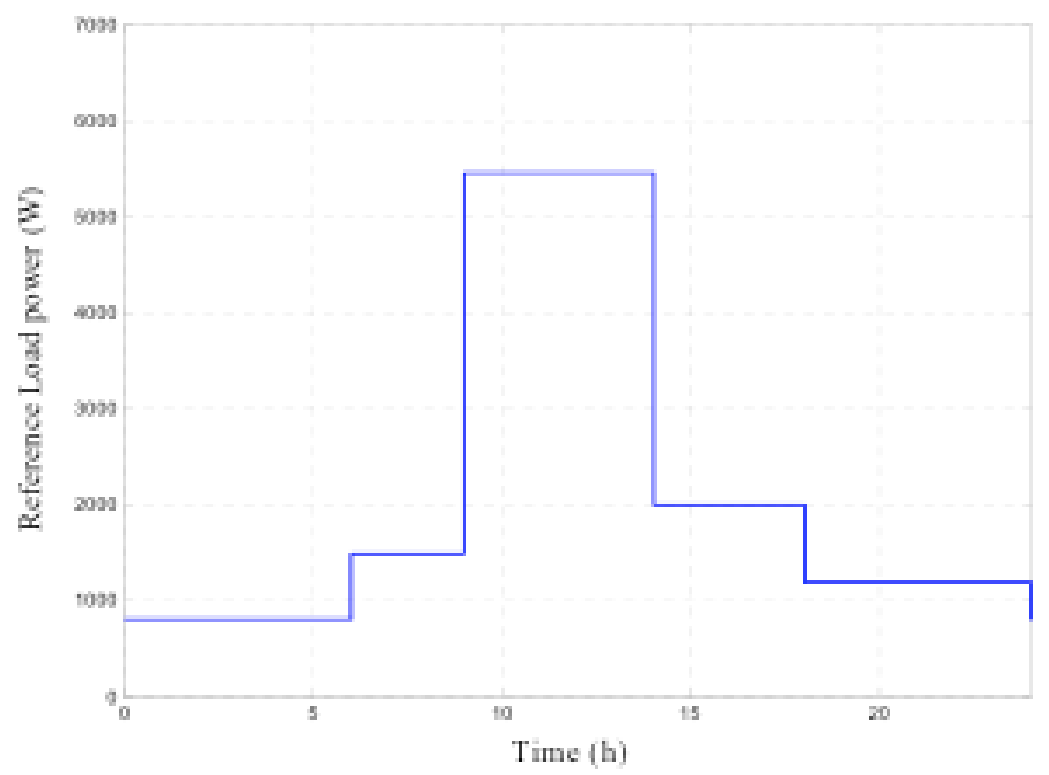

Fig. (5). Load profile.

Table 3. Modified Rule Base of the FLC

\begin{tabular}{|c|c|c|c|c|c|}
\hline $\mathbf{e}$ & NVB & NVB & ZE & PS & NS \\
\hline \hline NB & NVB & NB & NB & ZE & ZE \\
\hline NS & NB & NB & NS & PS & PB \\
\hline ZE & & NS & PS & & PVB \\
\hline PS & & & & \\
\hline PB & & & & \\
\hline
\end{tabular}

$1000 \mathrm{~W} / \mathrm{m}^{2}$ and at the maximum daily load of the load profile, illustrated in Fig. (5). Afterwards, the weight of each individual fuzzy control rule is evaluated successively, until the number of the actual used rules decreases to 17 . The useful fuzzy rules and the corresponding control surface of the designed FLC are indicated in Table 3 and Fig. (6), respectively.

\section{RESULTS AND DISCUSSIONS}

Initially, to indicate the high capability of the designed FLC (with the ON-OFF controller) in controlling the proposed PVDB hybrid energy system, the response of the load power using the ON-Off controller alone is indicated in Fig.
(7), which is carried out at the daily peak load of $5500 \mathrm{~W}$ and at insolation level of $1000 \mathrm{~W} / \mathrm{m}^{2}$. Thus, Fig. (7) indicates that using the classical ON-OFF controller alone yields a poor dynamic response for the load power that have not zero error at steady state. The transient response of the load power can be improved and at the same time the steady state error of the response can be eliminated from the system by using another controller that works simultaneously with the ONOff one, as shown in Fig. (8). This figure illustrates comparison between the relative responses of the load power using the classical PI controller and the designed FLC. This comparison is carried out, also, at the daily peak load of $5500 \mathrm{~W}$ and at insolation level of $1000 \mathrm{~W} / \mathrm{m}^{2}$. Thus, Fig. (8) indicates 


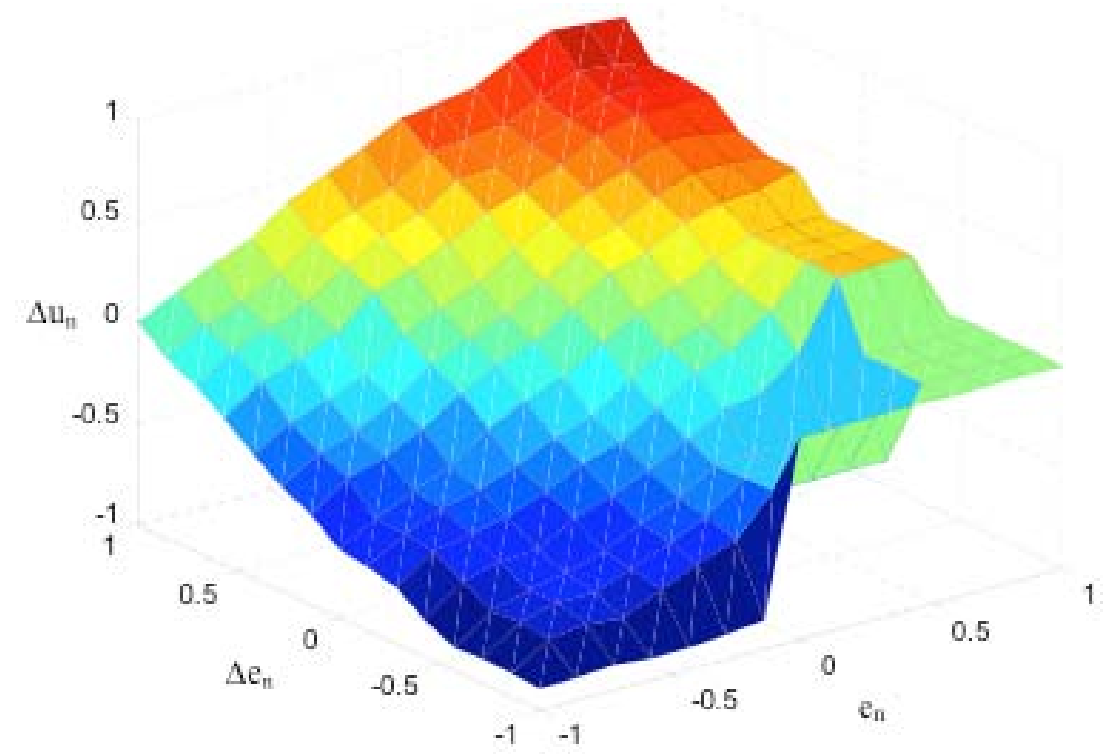

Fig. (6). Control surface of the designed FLC.

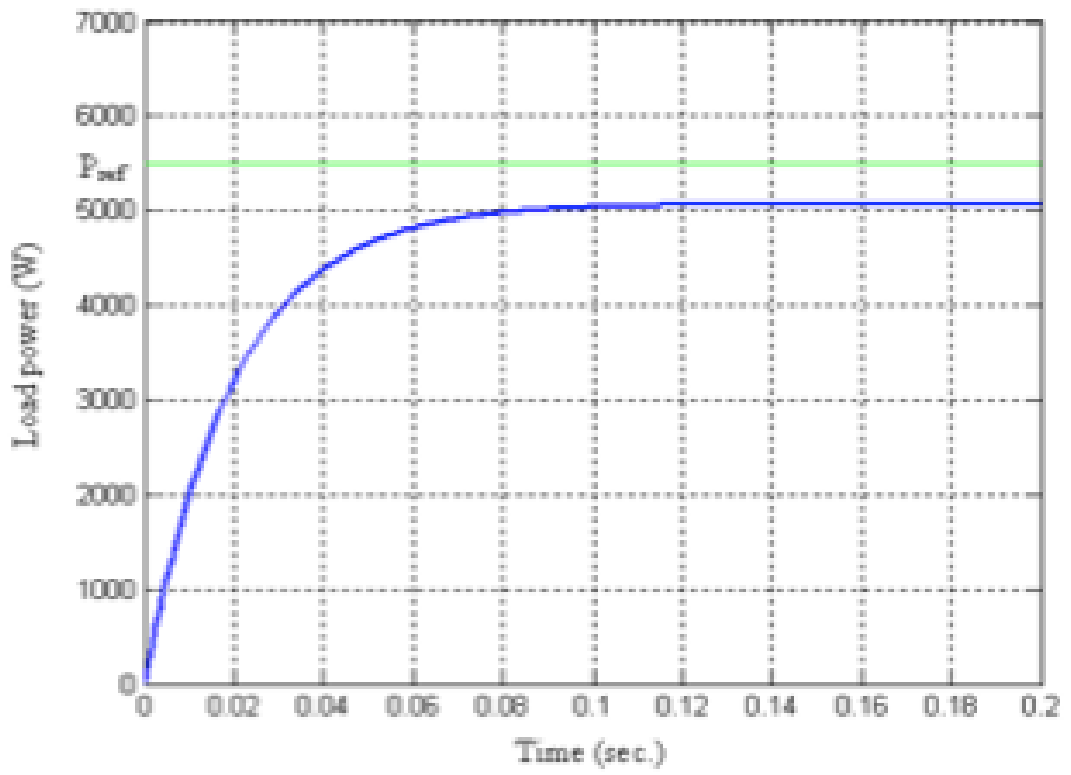

Fig. (7). Responses of the load power using the NO-OFF controller.

that the response obtained using the FLC is better than that obtained when the PI controller is used. This fact can be confirmed by illustrating the time domain specifications of the two responses, as shown in Table 4.

Also, to evaluate the relative robustness of both controllers in controlling the proposed PVDB hybrid energy system at different atmospheric conditions, the PVDB system is subjected to sudden variations in insolation level of 1000 $\mathrm{W} / \mathrm{m}^{2}, 200 \mathrm{~W} / \mathrm{m}^{2}$, and $800 \mathrm{~W} / \mathrm{m}^{2}$, respectively. The corresponding responses of the load power, using the two controllers, are depicted in Fig. (9). Thus, Fig. (9) indicates that when there is a sudden variations in the atmospheric conditions the response of the load power using the FLC is good and faster and having a lower integral of squared error (ISE) value compared to the case of using the PI controller. Therefore, this indicates the high suitability of the FLC over the classical controllers in controlling the PVDB hybrid energy systems.

As, the main objectives of the designed FLC and the ONOFF one are to reliably cover the load demand continuously at all days and at the same time to optimize the battery and diesel operation at all working atmospheric conditions. Then, the performance of the PVDB hybrid energy system is evaluated and compared, here, for two different days (one is cloudy and the other is sunny). Fig. (10) illustrates this comparison. Thus, it is clear that whatever the day is cloudy or sunny the load is completely covered, and this is achieved by optimally adjusting the battery and/or the diesel to supply the complementary power when the PV generation, which is shown to be variable according to the incident solar insolation levels for the cloudy and sunny days, is not enough. Also, it is cleared that the excess PV power is used to charge 


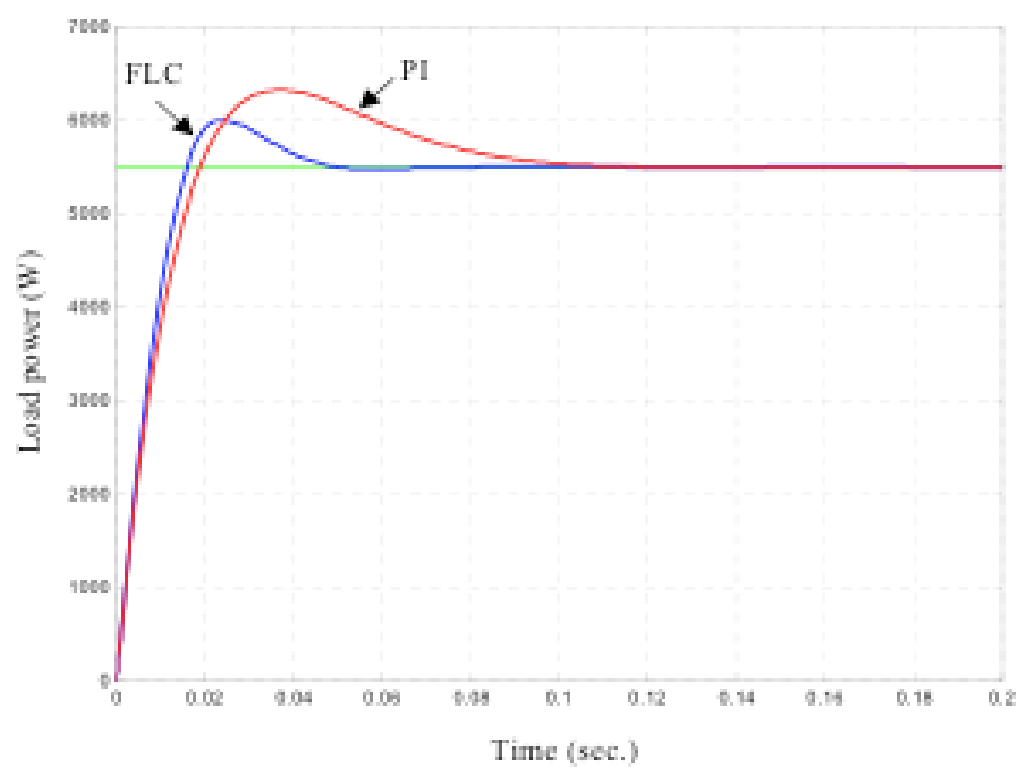

Fig. (8). Responses of the load power using the FLC and the PI controller.

Table 4. Time Domain Specifications

\begin{tabular}{|c|c|c|}
\hline Controller & FLC & PI \\
\hline \hline Specification & $0.016 \mathrm{sec}$. & $0.019 \mathrm{sec}$. \\
\hline Rise time $\left(\mathrm{t}_{\mathrm{r}}\right)$ & $0.042 \mathrm{sec}$. & $0.086 \mathrm{sec}$. \\
\hline Settling time $\left(\mathrm{t}_{\mathrm{ss}}\right)$ & $0.024 \mathrm{sec}$. & $0.037 \mathrm{sec}$. \\
\hline Peak time ( $\left.\mathrm{t}_{\mathrm{P}}\right)$ & $9.2 \%$ & $15 \%$ \\
\hline Max. overshoot $\left(\mathrm{M}_{\mathrm{P}}\right)$ & $123.763 \times 10^{3}$ & $151.904 \times 10^{3}$ \\
\hline Integral of squared error (ISE) & & 2 \\
\hline
\end{tabular}

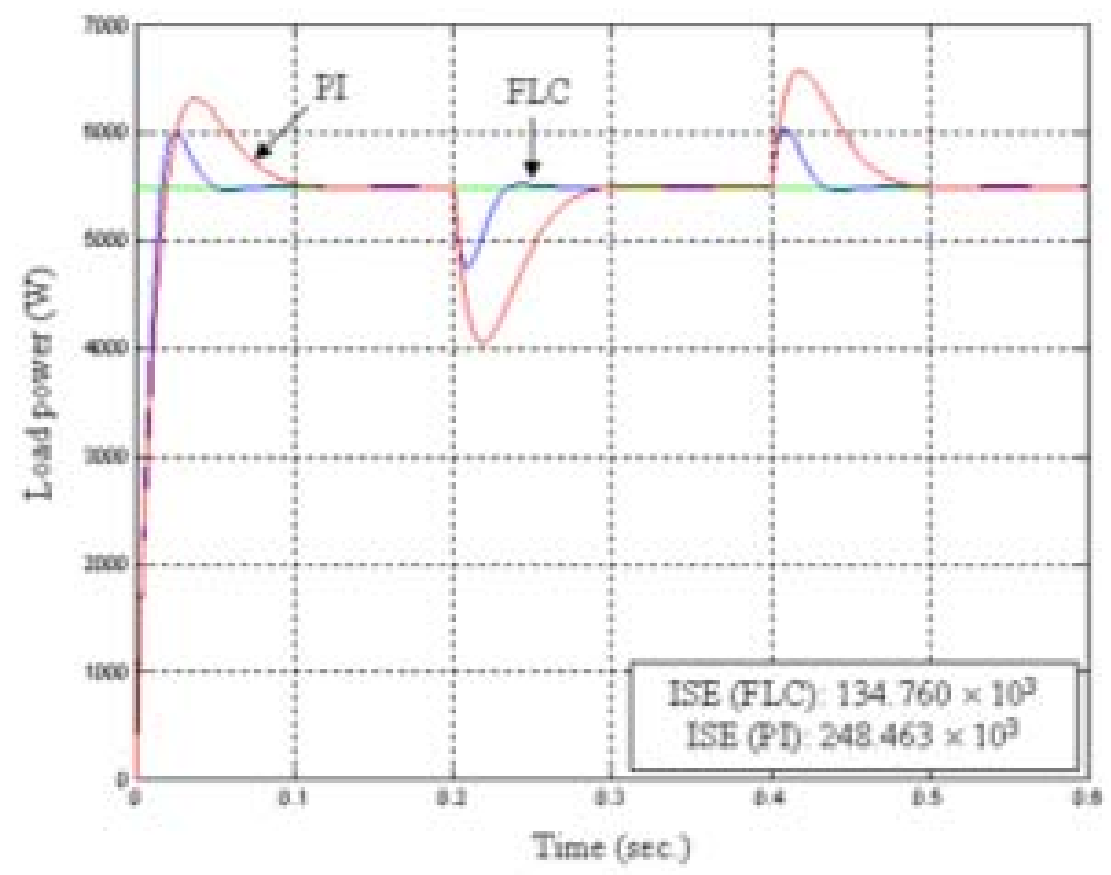

Fig. (9). Responses of the load power using the FLC and the PI controller at sudden variations in insolation. 

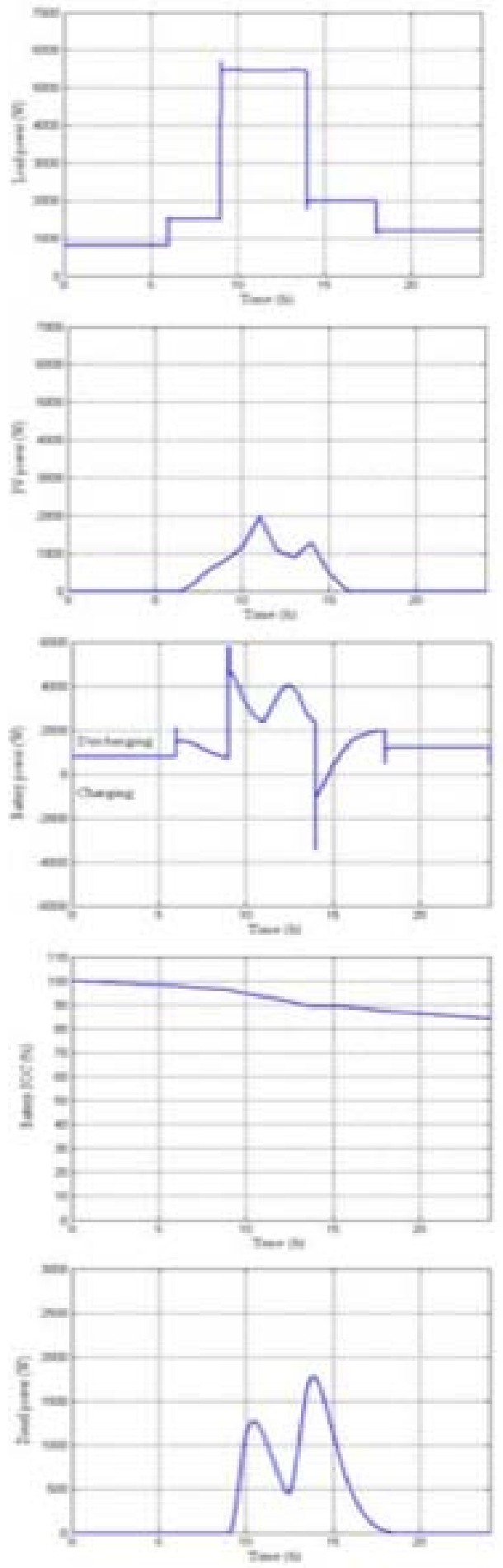

(a) During cloudy day
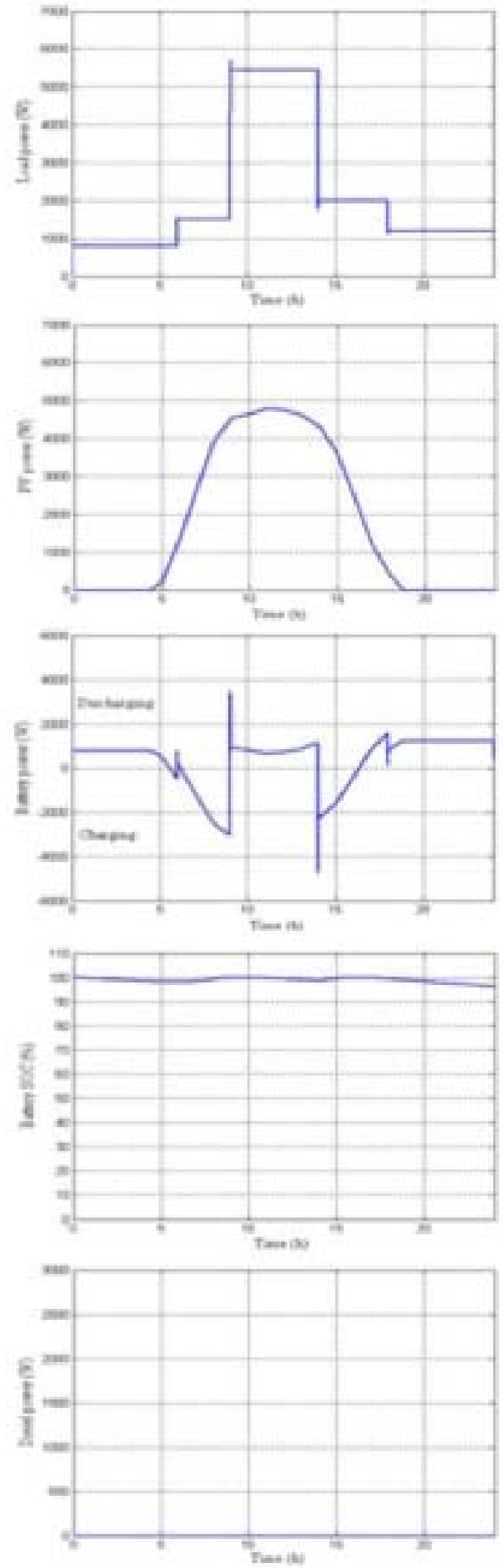

(b) During sunny day

Fig. (10). Performance of the PVDB hybrid system during two different days.

the battery (i.e., increases the battery state of charge SOC), especially during the sunny days. Moreover, the diesel generator is shown to operate only during the cloudy days; to supply the deficit in peak load power in conjunction with the system battery.

\section{CONCLUSION}

An operational control technique, based on using the FLC and the commonly used ON-OFF controller, is devel- oped and applied to the proposed PVDB hybrid energy system. This control technique aims to reliably satisfy the system's load, and at the same time to optimize the battery and diesel operation at all working atmospheric conditions. The proposed PVDB hybrid energy system is modeled and simulated using MATLAB-SIMULINK and FUZZY toolbox. The FLC is, mainly, designed to overcome the nonlinearity and the associated parameters variation of the components included in the PVDB hybrid energy system; therefore yield- 
ing better system's response at both transient and steadystate conditions. Through simulation work, the proposed PVDB hybrid energy system with using the FLC is compared to that with using the conventional PI controller. Where, the obtained simulation results indicate that the response of the load power in case of using the FLC is better and faster than that obtained in case of using the PI controller at all atmospheric conditions. Also, the obtained performance of the PVDB hybrid energy system, using the designed FLC, during two different days indicates that the load is continuously satisfied at all working days through optimizing the battery and diesel operation.

\section{REFERENCES}

[1] Al-Alawi, A.; Al-Alawi, S.M.; Islam, S.M. Predictive control of an integrated PV-Diesel water and power supply system using an artificial neural network. Renewable Energy, 2007, 32, 1426-1439.

[2] Moseley, P.T. Energy storage in Remote Area Power Supply (RAPS) systems. J. Power Sources, 2006, 155, 83-87.

[3] Ashok, S. Optimized model for community-bsed hybrid energy system. Renewable Energy, 2007, 32, 1155-1164.

[4] Dufo-Lopez, R.; Bernal-Agustin, J.L. Design and control strategies of PV-Diesel systems using genetic algorithms. Solar Energy, 2005, 79, 33-46.
[5] Nelson, D.B.; Nehrir, M.H.; Wang, C. Unit sizing and cost analysis of stand-alone hybrid wind/PV/fuel cell power generation systems. Renewable Energy, 2006, 31, 1641-1656.

[6] Dote, Y. Introduction to Fuzzy Logic. Proceedings of IEEE $21^{\text {st }}$ International Conference on Industrial Electronics, Control, and Instrumentation (IECON 1995), Orlando: FL, USA, 1995, Vol. 1, pp. 50-56.

[7] Lee, C.C. Fuzzy logic in control systems: fuzzy logic controllerPart I. IEEE Trans. Syst. Man Cybernet., 1990, 20(2), 404-435.

[8] Khouzam K.; Khouzam, L. Optimum matching of direct-coupled electromechanical loads to a photovoltaic generator. IEEE Trans. Energy Convers., 1993, 8(3), 343-349.

[9] Hunter R.; Elliot, G. Wind-Diesel Systems. Cambridge University Press: UK, 1994

[10] Fabero F.; Vela, N. Validation of Theoretical Model for Different $P V$ Batteries. Proceedings of $14^{\text {th }}$ European Photovoltaic Solar Energy Conference, Barcelona: Spain, 1997, pp. 2247-2250.

[11] Sousa, G.C.D.; Bose, B.K. A fuzzy set theory-based control of a phase-controlled converter DC machine drive. IEEE Trans. Ind. Appl., 1994, 30(1), 34-44.

[12] Hafez, A.M.; El-Dien, A.T. A DC Motor Speed Control System Based on Fuzzy Logic: An Experimental Approach. Proceedings of Al-Azhar Engineering Fifth International Conference. Cairo: Egypt, 1997, pp. 158-168.

(C) Abd El-Shafy A. Nafeh; Licensee Bentham Open.

This is an open access article licensed under the terms of the Creative Commons Attribution Non-Commercial License (http://creativecommons.org/licenses/by-nc/3.0/) which permits unrestricted, non-commercial use, distribution and reproduction in any medium, provided the work is properly cited. 